\title{
1. Broadening the scope of financial literacy to incorporate self-control, budgeting and heuristics
}

\section{Hersh Shefrin}

\section{INTRODUCTION}

The literature on financial literacy documents the degree to which financial knowledge across the consumer population is weak. The insights generated by this literature are valuable, and yet I suggest that there is room to broaden the scope of this literature. In particular, I suggest that the scope be broadened to focus on specific human capital relating to the way households budget and spend in the face of challenges related to self-control.

Findings described in a 2014 survey by Lusardi and Mitchell (2014), some of which I summarize below, identify three major issues associated with financial literacy: "(i) numeracy and capacity to do calculations related to interest rates, such as compound interest; (ii) understanding of inflation; and (iii) understanding of risk diversification." (p. 10). Notably, the literature on financial literacy is largely concerned with identifying positive relationships between the quality of household decisions and the degree of financial literacy. In this respect, the evidence suggests that in relative terms, households with greater financial literacy are less likely to make investment mistakes, more likely to engage in retirement planning, more likely to set aside emergency funds, less likely to have costly mortgages, less likely to use high-cost sources of borrowing, and less likely to hold excessive debt. With respect to credit cards, Lusardi and Mitchell note that "while less knowledgeable individuals constitute only 29 percent of the cardholder population, they accounted for 42 percent of these charges ... Indeed, the average fees paid by those with low knowledge were 50 percent higher than those paid by the average cardholder." (2014, p. 8). In addition, Lusardi et al. (2017) document that financial knowledge accounts for between 30 and 40 percent of inequality in retirement wealth.

As for broadening the scope of questions addressed by the financial literacy literature, I note that virtually all of the behavior patterns 
described in the preceding paragraph pertain to saving and borrowing, but not budgeting and spending. Indeed, the literature on financial literacy is largely silent about household spending and budgeting decisions, despite household budgeting being a core concept in the microeconomic theory of the consumer.

Lusardi and Mitchell (2014) examine decision quality through the lens of a stochastic optimization framework in which households make simultaneous choices about investing in financial skills, investing in the capital market, and consumption over their life cycles. The optimization framework is highly complex, featuring stochastic labor income, stochastic shocks to medical expenditures, uncertain lifetimes, and stochastic returns to a risky asset that depend on the level of household financial skill.

Lusardi and Mitchell recognize the difficulties that come when "people must forecast their (and their partner's) survival probabilities, investment returns, pension income, and medical and other expenditures" (p. 26). Furthermore, they note the following: "Moreover, many of these financial decisions are once- in-a-lifetime events, including when to retire and claim one's pension and Social Security benefits" (p.26). They point out "that some people will rationally choose to invest little or nothing in financial knowledge" (p.9), but do not provide a framework for analyzing what households do when they are unable to solve complex stochastic optimization problems. Instead, they note the wide gap between the optimal behavior implied by their formal framework and the reality of suboptimal decisions relative to that framework. As the presence of such gaps suggests the possibility of improved household financial decision making through education, Lusardi and Mitchell mention the possibility of "crossfertilization between behavioral economics and its focus on choice architecture and the group proposing to educate people about financial basics" (p. 35).

Two important terms which do not appear in Lusardi and Mitchell (2014) are "self- control" and "heuristics". These terms, I suggest, are key to identifying fruitful directions in which to broaden the scope of the financial literacy approach. The issue is important, I suggest, for essentially the same reason that Shefrin and Thaler (1988) articulate in their discussion about the modeling of life cycle decisions. They argue that the policy implications for increasing household savings, which arise from a behavioral life cycle model involving self-control and heuristics, are very different from the implications from a neoclassical-based life cycle model. Evidence for the effectiveness of the behavioral approach is described in Thaler and Benartzi (2004).

In view of the literature suggesting that a majority of people live hand to mouth, one might ask about the degree to which budgeting would bring net benefits. In this chapter I discuss why budgeting challenges apply to 
rich and poor alike. Failure to budget can, and does, leave those living hand to mouth on food stamps even worse off than they would otherwise be. There is evidence that increasing the granularity of the budget process has helped some people in these circumstances. ${ }^{1}$ There is evidence that those who budget are more likely to hold emergency funds (Liao, 2019a, 2019b). There is evidence that those who budget for Christmas gifts are less likely to overspend than those who do not.

I do not suggest that budgeting is a panacea. On its own, budgeting will not induce households to make sensible choices about long-term care insurance, life insurance, or health insurance. ${ }^{2}$ See Gottlieb and Mitchell (2019) on the impact of narrow framing, and Huffman et al. (2017) on the relationship between impatience and economic behavior among the elderly.

What I do suggest is that there is a need for formally broadening the financial literacy framework to include self-control, budgeting and heuristics as foundation concepts. In this regard, I recommend making much greater use of formal behavioral models, such as those described in Shefrin (2020), so as not to rely on complex neoclassical stochastic optimization models that are completely at odds with the manner in which most households, rich and poor, make decisions about spending, saving and borrowing. This is important because household consumer decisions can exhibit features associated with the theory of the second best. In this regard, below I discuss evidence that households use sensible heuristics to save during the year for Christmas gifts and pay the balances on their credit cards in ways that violate neoclassical first order conditions for optimality. The point is that most households might not be facing a neoclassical optimization problem, perhaps because they are psychologically unable to comply with such conditions. For these households, it is important to ask what is sensible, achievable behavior, and that question should be addressed in the context of a behavioral model.

As noted above, Lusardi and Mitchell (2014) recognize the large gap between the assumptions underlying their formal optimization framework and the suboptimality characterizing real world household behavior. Indeed, as I discuss below, many people do not plan their household finances to deal with issues such as Christmas holiday spending or retirement (Lusardi and Mitchell, 2007), and only a small minority say that they engage in regular household budgeting. In view of the large gap, Lusardi and Mitchell (2014) call for cross-fertilization to bring behavioral perspectives to bear on this issue. I agree with their position, which is why I suggest broadening the scope of the financial literacy literature so that it builds on a behavioral base involving self-control, budgeting and heuristics. I suggest that doing so provides the opportunity to identify household behavior that is psychologically feasible, sensible and welfare improving, even if 
inconsistent with neoclassical optimizing conditions. In this regard, the planner-doer models proposed by Shefrin and Thaler (1980), Thaler and Shefrin (1981) and Shefrin and Thaler (1988) are structured as constrained optimizations, with some constraints pertaining to behaviors, including nudges in the sense of Thaler and Sunstein (2008), that are psychologically feasible.

The issue about nudges is important because in planner-doer models, changing behavior patterns can be psychologically costly and require effort, so that knowledge in the form of financial literacy might not be sufficient for improved decisions. Human capital involves more than factbased knowledge and computational ability, but also mental processes that underlie action. Human capital pertains to both "knowing" and "doing". Financial literacy in the form of knowledge can only produce better decisions when paired with human capital associated with acting on that knowledge, a key issue for boosts. ${ }^{3}$

In the remainder of this chapter, I propose some ideas for broadening the scope of the approach to financial literacy. Section 2 describes how household budgetary issues are covered in the media. Section 3 discusses holiday budgets and self-control. Section 4 extends this discussion to general budgets. Section 5 introduces a general discussion about nature and nurture on household financial decisions. Section 6 summarizes recent findings about how nature and nurture impact the quality of financial decisions. Section 7 describes some practical issues associated with household heuristics, and section 8 concludes.

\section{BUDGETING ISSUES AS DESCRIBED IN THE MEDIA}

Lusardi and Mitchell (2014) mention the term "budget" in passing, as one item in a list provided by The US President's Advisory Council on Financial Literacy (PACFL 2008). This list pertains to "basic financial skills necessary to develop and maintain a budget, to understand credit, to understand investment vehicles, or to take advantage of our banking system" (p. 37).

Coverage in the American press generally suggests that most households find budgeting to be a challenging task. In this regard, consider three press articles.

Beginning with her own experience, Wong (2018) points out that many households engage in spending without keeping track of what they purchase, fail to understand the opportunity cost of repeated small purchases made over time, can be vulnerable to unwise impulse purchases, and 
establish choice architectures in which personal saving is placed at the end of the decision process order instead of at the beginning.

Sullivan (2019) draws on work done by Merrill Lynch's private banking and investment group, which shows that even wealthy Merrill clients are challenged by household budgeting. Wealthy households do not typically encounter difficulty putting food on the table, as is the case with some of their low-income counterparts. However, wealthy households have a great many budget items, and that makes for a very complex budgeting task. The list of items includes travel, automobiles and wine, charitable contributions, major gifts to friends and family, and taxes. ${ }^{4}$

Notably, the Merrill Lynch report points out that wealthy households are not immune from making impulse purchases. Kornelis (2019) reports the results of interviews in which he asked interviewees about their views on how Americans waste money, the reasons why, and what American households might do differently to spend more wisely. Interviewees identified as sources of waste the following: repeated small-dollar purchases such as coffee and bottled water; quick consumable items, especially food and beverages; unplanned grocery-store trips; and unnecessarily large homes.

Among those interviewed by Kornelis was David Bach, a wealth management professional known for criticizing Americans for daily purchases of latte, at the same time as they save insufficiently. As for reasons why Americans waste money, interviewees suggested that households spend money unconsciously, by habit more than deliberate choice; they indulge themselves on quick consumables because of difficulty delaying gratification; a lack of time to plan properly in order to avoid unnecessary grocery shopping trips; and wanting a large house as a symbol of success, so-called conspicuous consumption. As for what to do differently, interviewees suggested tracking expenses, planning meals and grocery shopping a week in advance; before purchasing a quick consumable, stop to ask if the purchase is a necessity; and doing some research on new techniques for designing smaller homes that contain impressive features.

\section{HOLIDAY BUDGETS AND SELF-CONTROL}

One of the points in Wong (2018) is that households routinely establish choice architectures in which personal saving is placed at the end of the decision process order instead of being at the beginning. Specifically, she writes: "being good with money, most experts will say, starts with a budget. If you pay yourself first - save a portion of your money before you spend it." This is a practice that Wong claims to follow herself.

Holiday purchases are an important component of retail purchases, 
and therefore are important for household saving and budgeting behavior. Consider how holiday saving practices illustrate the notion of "paying yourself first" and what holiday spending practices tell us about general purchasing behavior.

Thaler and Shefrin (1981) opens by describing a "Christmas club", which is a savings product offered by financial institutions to help people save money throughout the year to spend on Christmas gifts. Christmas clubs are structured with the option for automatic deposits, a penalty for withdrawing before November, and paying lower rates of interest than regular savings accounts. See Semczuk (2017).

Notably, the combination of withdrawal penalty and low interest rates implies that households that use Christmas clubs will operate strictly within their budget sets, a property that violates the assumptions of neoclassical rationality. Yet, it might be reasonable for someone who is struggling to achieve self-control to make use of a Christmas club.

The use of Christmas clubs is one example of holiday shopping behavior, and provides a focal point for investigating household budgeting. Christmas clubs were once routinely offered by commercial banks, but as Semczuk (2017) notes, these accounts are now offered mostly by credit unions, often called "holiday savings accounts". That banks stopped offering Christmas clubs raises the question of whether households' aggregate need for holiday savings discipline has declined over time, whether superior alternatives have emerged, or whether instead their demand for self-control solutions has declined.

Shefrin (2013a, 2013b, 2013c) describe some key findings about holiday budgeting. ${ }^{5}$ Approximately 55 percent of households set holiday budgets. Most do so during November and December, setting vague "plans" in early November and more formal budgets thereafter. Approximately 36 percent of those who set holiday spending budgets overspend those budgets. Households who keep to their budgets spend 63 percent less than those who spend more than they had planned (in November). The least accurate of those who engage in holiday budgeting plan to spend either less than $\$ 100$ or more than $\$ 749$, and on average overspend by about 30 percent.

\section{GENERAL BUDGETS AND SELF-CONTROL HEURISTICS}

The general findings reported in the previous paragraph suggest that for many, budget compliance is a challenge. Wong (2018) makes this point when she writes that when she actually tracked the purchases she "was 
tempted to make" she realized that a great many of those purchases were "mindless, impulsive items".

There is good reason to believe that tracking purchases represents a major challenge for households. Survey data from FINRA focused on financial literacy indicates that 61 percent of sampled households report that they find it either somewhat difficult or very difficult to cover all their expenses and pay all their bills. See FINRA's website http://www.finra.org/ and Lusardi (2011).

Consider the budgeting question asked in the financial literacy survey. Less than 1 percent of households answer yes to the following question: "Does your household have a budget? A household budget is used to decide what share of your household income will be used for spending, saving or paying bills." Just under 50 percent respond by saying that they do not know, and about the same percentage respond that they prefer not to say. About 1 percent answer no, similar to the response rate for yes. ${ }^{6}$

By way of contrast, Lusardi and Mitchell (2014) use the 2004 Health and Retirement Study (HRS) to report that with respect to the three main financial literacy issues - compound interest, inflation and stock risk - the percentage of those deemed to be financially literate on each issue respectively are 67 percent, 75 percent, and 52 percent, with only 34 percent of the sample being financially literate in all three areas. In addition to providing answers to financial literacy questions, respondents could also respond that they do not know, or prefer not to say. Less than 4 percent responded that they did not know, while the "don't know" responses were about 10 percent except in the case of stock risk, where the "don't know" rate was 34 percent.

A useful way of thinking about household budgeting is in terms of the two-stage budgeting "envelope technique" (Gorman, 1996). ${ }^{7}$ Households who use this technique set aside envelopes at the beginning of the month, with each envelope containing cash to be spent on a specific category over the course of the month. Categories can be broadly defined such as "grocery shopping" and "automobile expenses"; or they can be more narrowly defined such as "meat and fish" and "gasoline". Households that employ the envelope technique successfully plan, track and control their spending patterns relative to the categories associated with their envelopes.

Categorization involves the concept of "mental accounting" (Thaler, 1985), a concept that lies at the heart of behavioral life cycle theory (Shefrin and Thaler, 1988). Households employing the envelope technique that define categories narrowly will exercise more detailed planning, tracking and control than households that define categories more broadly. ${ }^{8}$ As discussed in Shefrin (2020), which extends the model in Shefrin and Thaler (1988), the use of broadly defined categories opens the possibility 
of having to rely on willpower to face temptation in order to deal with impulse purchases. A household with a weakness for "junk food" that has but one envelope for food, is vulnerable to overspend on junk food relative to healthy food.

In many cases, households purchase and consume different goods and services sequentially rather than simultaneously. This has important implications for the relationship between consumption and budgeting. Households concerned about overspending on junk food might employ a heuristic of the form "eat dessert last", because "eating dessert first" too easily leads to overconsumption of dessert relative to more healthy foods. A key feature of informal budgeting is its reliance on choice rules involving local satiation ("eating until you are full"), which is why the sequence of goods and services consumed and/or paid for, is important. ${ }^{9}$

Households that use many envelopes when they budget can generally be characterized as having strong budget processes. The lower the number of envelopes, the weaker the budget process. A single envelope process is weak. A zero envelope process in combination with cash and a credit card is weaker still, because it allows households to make impulse purchases today by borrowing at high interest rates against future income.

At the same time, some people use multiple credit cards to help themselves budget, by dedicating each card to only one category of purchases (Shefrin and Nicols, 2014). This is a variant of the envelope technique. ${ }^{10}$ Nicols and I used cluster analysis to differentiate our sample of credit card users from each other. We identified four distinct clusters, one of which featured people with multiple credit cards. Specifically no member of this particular cluster reported using a single card. Relative to the sample averages, the members of the multi-card cluster were somewhat older, more apt to use their credit cards for everyday purchases, less likely to set specific spending goals, more apt to engage in impulse buying, more apt to attach high importance to having control of their finances, the most confident that they managed their finances well, and the most likely to pay their monthly credit card balances in full. Twenty percent of our sample fell into this cluster.

Gathergood et al. (2019) document that people carrying positive balances on multiple credit cards with varying interest rates engage in nonoptimal repayment behavior. Specifically, instead of first paying down the balance on the card featuring the highest interest rate, many instead pay down the balances proportionally across cards, in what Gathergood et al. call the "balance-matching" heuristic. That is, the balance-matching heuristic matches the ratio of card payments to the ratio of card balances.

I suggest that while the balance-matching heuristic might be nonoptimal in a neoclassical setting, it can nevertheless constitute "reasonable" 
behavior. By reasonable, I mean being able to maintain desired expenditure proportions across commodities; and interest minimizing behavior will typically interfere with that. People who use multiple credit cards to structure mental accounts for multicommodity budgeting purposes will be willing to pay a bit more interest to achieve control of their expenditures. For those who remember Christmas clubs, people were willing to forgo interest and flexibility by depositing money into Christmas clubs instead of savings accounts that paid higher interest rates. In both cases, the "interest penalty" is akin to a fee for self-control service, a fee they are willing to pay.

I am not suggesting that every household using multiple credit cards does so for mental accounting budgetary reasons, or that no household makes mistakes in the way it pays down the balances on several cards. In the Shefrin-Nicols (2014) database, there are four clusters, and the mean proportion of those in the other three clusters who use multiple cards is 22 percent. In this regard, the cluster range for multiple credit card usage is 0 to 31 percent. Notably, in the cluster featuring the highest control and confidence, 99 percent use a single credit card.

\section{NATURE, NURTURE, SELF-CONTROL, AND INTERPERSONAL DIFFERENCES: GENERAL ISSUES}

There are at least two important ways in which households might differ from each other. The first difference involves the strength of impulses that lead them to be vulnerable to self-control challenges when facing temptation. The second difference involves the ability to construct and follow strong budgetary practices. This section discusses aspects of these differences relating to the degree to which they are inherent, meaning determined more by nature than by nurture. ${ }^{11}$

Over the last thirty years, neuroscientists and psychologists have made dramatic advances in understanding the nature of the human brain and how people make decisions. Their research has led to the understanding that the brain operates as a system with many interlocking components. Some of those components are associated with conscious thought, others are associated with automatic processes such as breathing and walking, while yet others are associated with emotions and feelings. ${ }^{12}$ Most decisions, including decisions about spending and borrowing, feature a combination of fast and slow thinking. Sometimes fast and slow thinking are in conflict with each other. Some people think that they make unwise choices, yet find it difficult to change their behaviors. This is slow thinking. 
Some people might say they eat too much, and have to cut down on their calorie intake. Others might say they drive too quickly, and need to slow down. Others might say they spend too much time partying, and need to spend more time studying. In all of these examples, stating a desire to change behavior is easier than effecting change.

Most people have difficulty delaying gratification or facing immediate pain. The fast thinking part of our brain appears to be hard wired to resist instinctively the acceptance of immediate pain and the delay of gratification. Moreover, the slow thinking part is often at a disadvantage in terms of mental resources because change takes conscious effort. People might try to change, but self-control takes effort, and often the mental resources required tend to be greater than the mental resources available.

When it comes to self-control, nature matters. Some people are simply better than others at self-control, and neuroscientific studies have shed light on why this is the case. ${ }^{13}$ Consider the following experiment, reported in Hare et al. (2009). A group of volunteers, all self-reported dieters, were connected to some neuroscientific monitoring equipment and shown photos of fifty different foods. The monitoring equipment recorded brain activity as experimental volunteers examined and made decisions about these foods. Examples of foods were tempting items, such as candy bars, and healthy, staple items such as vegetables. The experimenter asked the volunteers to rate each food first on taste and then on health benefits. The experimenter then selected for each participant an index food that the participant rated in the middle for both taste and health benefits.

Subsequently, the experimenter presented participants with a series of choices, asking them to choose between accepting either the index food or one of the other foods. The question is: how did the self-reported dieters choose, especially when faced with foods that they rated high on taste and low on health benefits?

Tasty foods are tempting. That is why supermarkets display tempting candy bars at checkout counters. Did the self-described dieters always choose the index food over foods that were low in health benefit but high in taste? The answer is no: only some did. And this takes us to the central question about nature. What differentiated the natures of people who always made the healthy choices from the natures of those whose decisions were guided by taste?

The experimenters discovered that the differentiating factor turned out to be brain region activity. If we think about our brain as a circuit board with lights, we can ask what parts of our brain light up in key circumstances.

The prefrontal cortex is the region at the front of the human brain associated with slow thinking. The food choice experiment identified two regions 
in this part of the brain. For ease of discussion, let us call one region $\mathrm{V}$ (for the ventomedial prefrontal cortex, the vmPFC) and the other region D (for the dorsolateral prefrontal cortex, the DLpfc). Everyone uses region $\mathrm{V}$ to make value-laden decisions. When we face a choice, region $\mathrm{V}$ lights up. However, region D only lights up for people who balance health benefits against taste. This is because region $\mathrm{D}$ appears to modulate the activity of region V. Region D is like an internal voice, forcefully asking, as we think of reaching for a candy bar, whether we need the extra sugar or would instead benefit by choosing a more nutritious alternative.

Part of the reason why in key situations the brain regions of some people light up but not those of others has to do with genetic differences. New experimental evidence points to the importance of specific genes. One particular gene which appears to play a central role in respect to the issues being discussed here is the COMT gene. ${ }^{14}$ Different people can have different variants of this gene. The thing about the COMT gene is that it plays an important role both in learning and, as it turns out, in financial behavior. ${ }^{15}$

There is more to nature than genes. Age is also a factor. It turns out that the frequency of financial mistakes varies with age and follows a U-shaped pattern. That is, financial mistakes decrease with age until people reach their early fifties, and then they begin to increase. The declining pattern up to the early fifties is consistent with people acquiring more assets during their early and middle years. However, the increase in mistakes at older ages highlights the natural limits on individuals' financial decision-making that come with aging.

Recent research has provided major insights into the roles of nature and nurture on financial behavior (Cronqvist and Siegel, 2015). This research focuses on the question of from where an individual's saving behavior originates. People who manage to accumulate savings tend to be those with favorable habits for spending and borrowing. The aim of the research team investigating this question was to identify whether saving propensity is governed by parents instilling preferences into their children, or instead whether it is the result of individual-specific life experiences.

There is evidence suggesting that some parents make efforts to teach their children good saving habits. These efforts entail activities such as providing a piggy bank, opening a savings account, and emphasizing the benefits of a frugal lifestyle. However, the evidence is effectively anecdotal rather than systematic and comprehensive. Therefore, we lack good evidence about the effectiveness of parental efforts. Regardless of this, we know that parents tend to pass their saving propensities onto their children. In this regard, recent research helps us to understand the extent to which this similarity is genetic as opposed to the result of social transmission of behavior from parents to children. 
Cronqvist and Siegel analyze Swedish data pertaining to the saving behavior of identical and fraternal twins. The aim of the researchers conducting the analysis was to decompose the individuals' propensity to save into two components, one genetic and the other environmental. In this regard, the research methodology relied on the fact that identical twins share 100 percent of their genes, whereas fraternal twins typically share only 50 percent. Cronqvist and Siegel reasoned that if identical twins save in a way that is more like their parents than is the case for fraternal twins, then they could conclude that saving behavior is partly genetic in nature.

Genes do matter for saving behavior. The researchers found that genes explained about 33 percent of saving behavior for the individuals in their sample. Moreover, the effect is long lasting, and does not disappear later in life. An important finding is that parenting explains 40 to 50 percent of saving behavior for 20 to 25 -year-olds.

However, the parenting effect decays significantly and reaches zero for people in their forties. Therefore, parenting appears not to have a lifelong impact on the saving propensities of children. Not surprisingly, the effect of parenting on saving behavior is smaller when time for parenting is scarce. In addition, saving behavior turns out to be correlated with income growth, smoking, and body mass index. This fact is important because the correlations for smoking and body mass index are mainly genetic, not environmental; and even income growth is more closely related to genetic variables than environmental variables.

The previous paragraph focuses exclusively on nature. However, nurture definitely plays a role. The research indicates that wealth of parents and current socioeconomic status moderate genetic predispositions to particular saving behaviors. Cronqvist and Siegel summarize their main findings by saying that both the genetic component and lack of self-control are the primary drivers of saving behavior.

\section{NATURE, NURTURE, AND INTERPERSONAL DIFFERENCES: SPECIFIC RELATIONSHIPS}

Despite lacking data linking household financial behavior to variables such as COMT and DLpfc activity, it is possible to gain insight into the impact of nature and nurture on household behavior by using proxies. A recent study by Liao (2019a, 2019b) provides insight into the manner in which individual differences in variables that proxy for differences in variables like COMT-variant and DLpfc impact household behavior in respect to budgeting, spending, borrowing and saving. Liao studies the relationship 
among these activities by using panel (longitudinal) data from the National Longitudinal Survey of Youth Child and Young Adult (NLSY CYA).

The NLSY CYA follows approximately 6000 individuals between early childhood and adulthood. In respect of financial behavior patterns, these data provide information about household behaviors involving paying bills, using high interest loans, generating emergency savings, buying necessities, and budgeting and tracking expenses.

With respect to individual differences across households, the NLSY CYA provides data about personality traits, demographics, and cognitive abilities. With respect to personality traits, Liao focuses on variables related to attention-deficit/hyperactivity disorder (ADHD), and investigates how survey participants' behavior patterns described above are related to their ADHD scores. ${ }^{16}$ She finds that survey participants with more severe ADHD symptoms earlier in life subsequently display more problematic patterns. ${ }^{17}$

One item in the list of ADHD components pertains to impulsivity, strongly relates to self-control, and can be thought of as a proxy for DLpfc activity. Recall the discussion about impulse purchases in the section above describing media coverage of household financial behavior. Liao separated this variable to see whether it impacted behavior differentially, running her baseline regressions using just the "impulsive/acts without thinking" variable instead of the ADHD variable. The results look similar, suggesting that both phenomena, while possibly psychologically distinct, operate in similar ways.

Liao also grouped the list of ADHD components into the three primary presentations of ADHD, inattentive, hyperactive/impulsive, and combined. ${ }^{18,19}$ When she replaced the current ADHD variable with each of these two variables, the results appear to be similar. The main difference turns out to be that only the "impulsive/acts without thinking" and the hyperactive/impulsive group are significantly related to the likelihood of having credit card debt, while the inattentive presentation is not linked with having credit card debt. This finding is important, as credit card debt is one of the major household debt categories in the US, behind mortgage debt, student loans, and auto loans. ${ }^{20}$

A subset of the NLSY CYA data provides insight about the impact of budgeting. Data about budgeting activity is based on a single question that was administered in the years 1994, 1996 and 1998. In those years, the NLSY CYA asked young adults the following question: ${ }^{21}$

About how often do you use a computer to keep track of home finances, budget, or balance checkbook?

1. almost every day;

2. several times a week; 
3. about once a week;

4. less than once a week;

5. never.

Roughly speaking, about 14 percent of the subsample report engaging in some form of budgeting activity using a computer. Of those that do report keeping a budget, half do so less than once a week and a quarter do so once a week. ${ }^{22}$

As part of her general investigation, Liao ran baseline regressions on her subsample to include the budgeting question as well as ADHD as independent variables. In these regressions, the budgeting variable has a marginally negative effect on foreclosure/ repossession/bankruptcy and a significantly positive effect on have emergency savings. Notably it is insignificant for all other dependent variables. ${ }^{23}$

Liao's analysis of the data reveals three additional insights about budgeting. First, the propensity to budget is positively related to being male and net worth. Second, net worth, computed using household assets and debts for vehicles, homes, and credit cards, is concentrated in the range $\$ 0$ to $\$ 10000$. The net worth histogram is similar for households that budget compared to those that do not. For both, the relative frequency of negative net worth drops sharply at $\$ 0$, and is somewhat smaller for the subset of households who budget. Third, those with ADHD are less leveraged if they budget.

The subsample that includes responses to the budgeting question is about one quarter the size of the full sample. Notably, estimates on ADHD for the subsample are similar to the full sample (both in terms of magnitude and significance). Therefore, there is reason to be confident that the findings about the impact of the budgeting variable are robust.

In her regressions, Liao controls for cognitive ability, which she finds to be positively related to households' ability to make ends meet. Cognitive ability might not be a perfect proxy for COMT-variant, but does appear to feature statistically significant relationships with variables such as foreclosures, repossession and bankruptcy.

Liao does not examine issues of nurture directly, but does control for unobserved family-level heterogeneity. She reports that unobserved familylevel heterogeneity, including the genetic component of the determinant of ADHD symptoms, appears "to drive the relationship between ADHD symptom severity and late debt payments, as well as the relationship between ADHD and having high-interest debt such as payday loans and credit card debt." She also notes the possibility that "one's family network can provide insurance via resource pooling, explaining the variation between ADHD symptoms and payday loans and late debt payments." 


\section{PRACTICAL BUDGETING HEURISTICS}

Regardless of whether households have strong or weak budgetary processes, behavior patterns are likely to be heuristic in nature. People use heuristics as simplifying devices because the scope of the decision tasks they face as consumers is overwhelmingly complex. This section describes examples of heuristics for spending and borrowing.

By their nature, household heuristics tend to be both fast and frugal. Frugal heuristics only require small amounts of information to implement. Fast heuristics are easily executed (see Gigerenzer, 2008). Most heuristics are aids to slow thinking, and bear in mind that slow thinking takes effort. Therefore, households need to rely on heuristics that require only limited information; and they need to rely on heuristics that enable them to make decisions quickly.

Consider some examples of fast and frugal heuristics for spending. ${ }^{24}$ The first involves an application of what is called the "recognition heuristic": in a choice between two products, choose the product whose brand is most recognizable.

A second example is to use "one reason" heuristics such as "take the best": in a choice between two products, look for one good reason to choose between them by ranking the most important attributes in order and starting with the first attribute. If price tops the list of attributes, then choose the lower priced product. If the two products have the same price, base the choice on the second most important attribute, and so on. The consumer marketing literature documents the use of fast and frugal heuristics in practice. For example, there is evidence from the United Kingdom that in making healthcare decisions, many people use one reason decision making (see Ryan and Hughes, 1997; Bryan et al., 1997; Ratcliffe, 1998). This appears to be the case in choices between treatments for miscarriage, knee problems, and liver transplantation. Keep in mind that one reason decision making is non-compensatory in nature, meaning that people do not evaluate tradeoffs between product attributes. In this regard, a US automobile manufacturer that surveyed car buyers found that threequarters of those surveyed made their decisions using non-compensatory heuristics.

A third example is "satisficing": in shopping for a product to fill a need, establish a standard for what is "good enough", and keep searching through product choices until finding one that is good enough. Then buy it, and move on to another task. ${ }^{25}$ An interesting example of price search comes from a study about student purchases of textbooks at the University of Texas (UT) (see Norman et al., 2008). Students purchasing their textbooks at UT have a choice. They can purchase at the University Co-op, 
which is convenient and effectively guarantees on-time delivery and stated quality. Or they can search using other alternatives such as online multisite buyers, where they can pay approximately 40 percent less than the Co-op price but face the added inconvenience and risk of late delivery and poor quality. Research shows that students implement a reasonable low price search heuristic to balance the benefits and costs of additional search. Notably, the students who have familiarity with statistics come closest to implementing an optimal search strategy. ${ }^{26}$

In line with the "nudge" framework of Thaler and Sunstein (2008), households typically need to be motivated to follow specific heuristics, even when they are fast and frugal. In this regard, consider an approach called "Borrow Less Tomorrow" (BLT) for addressing debt. BLT has three parts which are structured to address behavioral issues. The three parts are: (1) a decision aid; (2) a commitment option; and (3) reminders. The decision aid seeks to help households in debt to develop specific goals, and heuristic plans. Because "you can lead a horse to water but cannot make it drink", the commitment option helps to motivate borrowers to follow the recommended plan to achieve those goals; and reminders help to redirect borrowers' attention, should they become distracted. ${ }^{27}$

Here is additional detail about how the original study for BLT was carried out (see Karlan and Zinman, 2012). The decision aid was a simple repayment schedule calculator, which was used to take a specific debt, usually one featuring both a high balance and a high interest rate, and establish a concrete plan for paying down that debt more quickly. In this regard, tax preparers typically reviewed a number of hypothetical payment schedules with a client. These reviews served to demonstrate the possible reductions to repayment time and total interest paid that can come from making small increases in monthly payments. Having drafted a repayment schedule with equal monthly payments, preparers then presented clients with the option of making accelerated payments. Clients walked away with repayment schedules contrasting their original repayment pattern and accelerated payment pattern.

The commitment device involved peer pressure. Clients were given the option of signing up one or more "peer supporters". These supporters were to be notified and asked to provide encouragement (but not financial support), in the event that the client's payments fell behind schedule.

Reminders were generated monthly, if clients accepted them. Reminders could be received either by phone or email. The purpose of reminders was to keep the clients' debt reduction goals and plans at the forefront of their minds. ${ }^{28}$

The BLT study had one other interesting feature in that the authors controlled for several psychological or behavioral biases. In this regard, they 
asked survey questions about self-control, numeracy and attention. One self-control question pertained to whether clients would choose smaller immediate rewards over larger distant rewards, even though they would always choose larger rewards if the rewards were delayed in time. A second self-control question asked the following: "I often find that I regret spending money; I wish that when I had cash, I was better disciplined and saved my money rather than spent it." The study authors found that 77 percent of clients responded that they strongly agreed with or partly agreed with that statement. Questions about attention asked how frequently clients think about their financial situations. Thirty percent said something less than "a lot". Finally, with respect to numeracy, the study authors assessed a measure of exponential growth bias associated with interest compounding from open-ended, intuitive responses to a question on population growth. They found that 49 percent underestimate, 34 percent overestimate, and 6 percent provide approximately the correct answer.

\section{CONCLUSIONS}

Although the literature on financial literacy has documented important relationships between financial literacy and the quality of household financial behavior, I suggest broadening the scope of the literature to include behaviors related to self-control, budgeting and heuristics. In this respect, I argue that broadening the scope of the financial literacy literature so that it builds on a behavioral base involving self-control, budgeting and heuristics, provides the opportunity to identify household behavior that is sensible and welfare improving, even if inconsistent with neoclassical optimizing conditions.

Media coverage of problematic household behaviors identifies impulse spending and weak processes for budgeting as major concerns. Survey data make it clear that only a small proportion of households engage in formal budgeting. Households that establish weak budgets, and are vulnerable to impulse spending, will tend to face difficulties making ends meet. A reasonable hypothesis is that those households with access to high interest rate loans, such as those through credit cards, will be apt to use credit card debt more than planned. While media coverage tends to be anecdotal in nature, it can prompt academic inquiry about the degree to which the anecdotal data is supported by larger data sets. In this regard, recent empirical work does establish that households that are more prone to impulsivity tend to make greater use of credit card debt.

The literature on financial literacy documents that in the aggregate, households fail to set aside sufficient emergency funds, so-called "rainy 
day" accounts. Recent empirical work establishes that households with weak budgetary processes are less inclined to establish rainy day accounts. It is possible that a common factor, such as being disciplined, underlies both being disciplined about budgeting and setting aside emergency funds. However, it is also possible that by engaging in detailed budgeting, households develop a deeper understanding of what their financial needs are, what types of risks they face, and therefore what amount of emergency funding is prudent for their circumstances. For decades, holiday budgets have been part of the discussion about household budgeting, largely because of Christmas clubs. Although Christmas clubs are less fashionable than they were in the past, holiday budgeting and spending continues to be an important issue. Households are much more apt to set separate holiday budgets than they are to engage in regular budgeting. This is an interesting issue that is part of a general self-control phenomenon that has been analyzed in the psychology literature.

Budgetary skills constitute an important component of households' human capital. Setting and following budgets involves the use of heuristics, especially for the majority of households whose budget processes are informal. This is important because properly modeling this type of human capital cannot be easily accomplished through a neoclassical optimization model in which human capital is treated as a generic stock variable whose presence increases the returns on assets held. Rather, budgetary human capital needs to be modeled explicitly as part of the heuristic processes that govern household behavior. The relevant point about Christmas clubs is that their historical use pertains to the question of whether households needlessly gave up interest income and constrained themselves unnecessarily. From a neoclassical perspective, they did. From a behavioral perspective, households were willing to pay for a self-control mechanism that would help them establish holiday budgets. A similar statement might apply to the balance matching heuristic associated with the use of multiple credit cards.

In terms of future research, the approach described in this chapter suggests a greater focus on the impacts of nature and nurture on household financial decision making. Improvements come with a better understanding of the constraints imposed by nature and the limits associated with nurture. I suggest that neoclassical optimization models fail to capture important psychological features of the way people make decisions and change behavior. In contrast, the planner-doer models proposed by Shefrin and Thaler (1980), Thaler and Shefrin (1981) and Shefrin and Thaler (1988) are structured as constrained optimizations, with some constraints pertaining to behaviors, including nudges in the sense of Thaler and Sunstein (2008), that are psychologically feasible. The issue about nudges 
is important because in planner-doer models, changing behavior patterns can be psychologically costly and require effort, so that knowledge in the form of financial literacy might not be sufficient for improved decisions.

\section{ACKNOWLEDGMENT}

I thank Shabnam Mousavi for inviting me to write this chapter. I am especially grateful to Chi Liao for sharing key insights from her work with me, to Annamaria Lusardi for providing me with unpublished information from her database, and to Olivia S. Mitchell for her comments and reflections.

\section{NOTES}

1. For a discussion about budgeting frequency, see https://advanced-hindsight.com/blog/ managing-month-food-stamps/.

2. I thank Olivia S. Mitchell for this point.

3. See Shefrin (2013d) for a discussion about why the amount of financial education focusing on conceptual and computational knowledge, by itself, has limited effectiveness in contrast to the impact of action-oriented educational programs. This is important for boosts, which can be viewed within the NUDGES framework of Thaler and Sunstein (2008) as interventions which rely for behavioral change on knowledge which impacts the agency of actors rather than exploiting psychological phenomena such as status quo bias. Boosts emphasize the U-component of NUDGES, increasing actors' understanding of the mapping from actions to consequences.

4. The Merrill Lynch study discusses many spending outlets for wealthy households, both voluntarily or involuntarily, such as mortgage payments on their home (or homes), insurance, maintenance, repairs and occasional remodeling.

5. The survey data underlying these findings was generated in two waves, the first wave between 2 November 2010 and 5 November 2010, and the second wave between 14 January 2011 and 19 January 2011. The surveys were commissioned by Chase Bank, and were administered (over the Internet) and analyzed by the firm Stratalys Research. The full sample consists of 1208 households, with a subsample of 800 participating in both waves. Households were selected randomly across the United States. Respondents had to be aged 18 or older.

6. I thank Annamaria Lusardi for providing me with these data.

7. Gorman's paper appears in Gorman et al. (1996), which describes the paper as follows: "This paper is from an unpublished typescript (University of North Carolina, 1970), and is the first of a series of papers in Part I of the book on the general subject of budgeting - the rather vague notion that households, organizations, or governments first allocate a given total expenditure to various subsets of commodities, such as 'food', 'recreation', or 'saving'. Only after the allocations to these broad sectors have been specified, does the agent or organization decide how to split each sectoral expenditure among its component parts, such as the particular food commodities. The set of papers assumes that the agent or organization has a well-defined preference ordering over all relevant commodities, and hence the problems are cast in the context of consumer theory (purely for expositional purposes). Reinterpreting the results in terms of a firm presents no special difficulties, and allows a variety of problems to be discussed. 'Two- 
stage budgeting' supposes that the correct intersector allocations have been made, and then shows that separability of that sector is necessary and sufficient for the resulting intrasector allocations to be optimal."

8. Gorman's work on two-stage budgeting was motivated by anecdotal observations of households behaving in this manner. Gorman sought to develop a neoclassical model in which such behavior was utility maximizing. In contrast, the behavioral approach makes no attempt to rationalize two-stage budgeting, but instead treats the technique as a way of simplifying a very complex task.

9. For a formal behavioral budgeting framework that models informal as well as formal budgeting, see Shefrin (2020).

10. The multiple credit card "envelope budgeting" behavior pattern was described by William Wallace, President of Chase Card Services, at a Chase media event that took place in New York City on 5 May 2010. Wallace reported that a Chase research team had identified the behavior in Chase's user data, and that it struck them as sensible but not rational.

11. Goda et al. (2019) discuss interpersonal differences in respect to savings behavior, noting that some savings plans can induce people to underspend rather than the reverse. Thaler and Shefrin (1981) make this general point, and emphasize that this can occur even when saving patterns are the result of internal rules governed by habit as well as external rules governed by a plan such as an automatic deduction plan.

12. Kahneman (2011) describes a two-system framework that some psychologists use to describe human thought, in which one system is identified with fast thinking and the other with slow thinking. The fast thinking component involves activities that are largely automatic and feel effortless. The conscious, slow thinking components are purposeful.

13. The remainder of this section is largely taken from Shefrin (2013d).

14. COMT is short for Catechol-O-Methyltransferase.

15. Notably, one particular variant of this gene significantly increases the availability of dopamine in the prefrontal cortex of the brain. Dopamine is a neurotransmitter which a large body of neuroscience research has shown to be critical for learning from new outcomes. The favorable variant of the COMT gene impacts cognition mediated by the prefrontal cortex, specifically executive control and working memory, with the favorable variant being generally associated with better performance. Experimental evidence tells us that nature definitely matters for financial decision making, just as it matters for athletic ability and physical traits. People having the COMT-gene variant that significantly increases the availability of dopamine in the prefrontal cortex of the brain appear to make better financial decisions. Because this same gene variant is also associated with better learning, it is plausible that people with this genetic variant have learned to be more financially literate than others, and to make better financial decisions. This might explain a finding by Mandell (2008) that traditional financial education appears to have had so little impact on financial behavior.

16. In the NLSY CYA, assessment of symptoms pertinent to ADHD is provided by survey participants' mothers, who rated their children on the following traits: in the previous three months:

1. has difficulty concentrating, cannot pay attention for long;

2. is easily confused, seems to be in a fog;

3. is impulsive, or acts without thinking;

4. is restless or overly active, cannot sit still; and

5. has a lot of difficulty getting [his/her] mind on certain thoughts.

There were three possible responses to each, which were (1) often true; (2) sometimes true; and (3) not true.

17. Specifically, those with more severe symptoms of ADHD experience more difficulty paying their bills, are more likely to be delinquent on bill and loan payments, have a greater likelihood of having an account in collection, are more likely to have credit 
card debt and payday loans, are less likely to have emergency savings, are more likely to have delayed buying necessities, and are less likely to have any money left over at the end of the month. Some of these relationships are nuanced. For example, Liao reports that while ADHD symptoms remain positively associated with financial distress in general, family-level heterogeneity accounts for the relationship between ADHD and late debt payment, as well as the relationship between ADHD and having high interest loans.

18. The inattentive group sums the "has difficulty concentrating", "is easily confused" and "has difficulty getting mind off certain thoughts" questions and the hyperactive/ impulsive group sums the "impulsive/acts without thinking" and the "is restless or overly active" questions.

19. Liao points out that according to the Diagnostic and Statistical Manual of Mental Disorders, there are technically three presentations: combined, primarily inattentive, and primarily hyperactive/impulsive. See Reynolds and Kamphaus (2013).

20. The literature on payday loans is mixed in respect to impact on households. Martin and Keown (2017) report that payday lenders are less affluent than the general population, with 20 percent of borrowers earning less than $\$ 25000$ a year (only 1 percent earn more than $\$ 100000$ a year) and only 6 percent being full-time employees. Moreover, the majority of payday loans are used to finance ordinary household expenses (69 percent) and the loans are typically outstanding for five months. Bhutta (2013) reports finding little to no effect of payday loans on credit scores, new delinquencies, or the likelihood of overdrawing credit lines. Morse (2011) finds that access to payday loans lowers the likelihood of foreclosure after natural disasters by over 20 percent, and Morgan and Strain (2008) find that loss of access to payday loans results in increased bankruptcy filings. On the other hand, Skiba and Tobacman (2011) find that access doubles chapter 13 bankruptcy filings, and Melzer (2011) finds that access increases the incidence of having difficulty paying bills by 25 percent among lower-income households. Bertrand and Morse (2011) provide survey evidence that payday borrowers tend to make mathematical errors, where they underestimate the fees stemming from multiple renewals.

21. The results based upon the budget/computer are ancillary, and not part of the main body of Liao's paper.

22. In the data analyzed in Shefrin and Nicols (2014), the cluster of credit card users most prone to engage in impulse purchases, which comprised 27 percent of the sample, were 30 percent as likely to set specific spending goals (i.e., budget), about 7 times as likely to express low confidence in having control of their spending, and about 2.5 times as likely to express low confidence in using technology as those in other clusters. These findings suggest that adding the "computer" clause to the budget question in the NLSY CYA led to an upward bias of the proportion of households who set general spending budgets.

23. Liao's findings imply that credit card debt is driven by impulsivity, but not strength of budgeting behavior. What is somewhat puzzling is that while the budgeting variable itself is not significant in most regressions, its inclusion decreases the significance, and often magnitude, of the ADHD estimates. Notably, the effect of ADHD on late debt payment, payday loans, credit card debt, emergency savings, delaying the purchase of necessities, and the amount left at the end of the month are not statistically significant with the inclusion of the budgeting variable.

24. See Shefrin and Nicols (2014).

25. Using search heuristics entails knowing where to search. Bargain hunting households look to take advantage of group discounts. They use Internet searches to locate coupon codes. They seek sample sales, meaning sales at which manufacturers sell samples directly to the public. They also shop at outlet malls. Some workers consider switching from driving their own cars to public transportation, or form carpools. Others try telecommuting.

26. More sophisticated heuristics than those discussed here involve some consumer research in order to evaluate tradeoffs across different product attributes, such as gas mileage and size in automobile choice. In a perfect world, non-compensatory heuristics are 
suboptimal because most choices involve accepting tradeoffs, and tradeoffs are the basis for compensatory heuristics. However, in particular decision environments, tradeoffs introduce too much complexity for the limited information processing capabilities that households possess. As a result, non-compensatory heuristics might be good enough, even though imperfect.

27. The study underlying BLT took place in Tulsa, Oklahoma during the 2010 tax season, and is based on a sample of clients making use of free tax-preparation. The study focused on credit card debt and auto loan debt, and offered tax preparation clients the opportunity to participate in the BLT program as a way of reducing their household debt.

28. The results from the study were as follows. Of those offered the opportunity to participate in BLT, 41 percent made a plan. Of these, 27 percent accepted peer support, 41 percent made an escalating repayment plan, and 81 percent were sent reminders. For reminders, 44 chose phone, 37 percent chose email, and 19 percent opted not to be reminded. As for outcomes, 51 percent of clients who made a plan were on schedule after twelve months.

\section{REFERENCES}

Bertrand, M. and A. Morse, 2011. "Information Disclosure, Cognitive Biases, and Payday Borrowing", The Journal of Finance, 66(6): 1865-93.

Bhutta, Neil, 2013. "Payday Loans and Consumer Financial Health", Finance and Economics Discussion Series, Divisions of Research \& Statistics and Monetary Affairs, Federal Reserve Board, Washington, DC.

Bryan, B., M. Buxton, R. Sheldon and A. Grant, 1997. "The Use of Magnetic Resonance Imaging (MRI) for the Investigation of Knee Injuries: A Discrete Choice of Conjoint Analysis Exercise", paper presented at the Health Economists' Study Group Meeting, University of York, July.

Cronqvist, Henrik and Stephan Siegel, 2015. "The Origins of Savings Behavior", Journal of Political Economy, 123(1): 123-69.

Gathergood, John, Neale Mahoney, Neil Stewart and Joerg Weber, 2019. "How Do Individuals Repay their Debt? The Balance-Matching Heuristic", American Economic Review, 109(3): 844-75.

Gigerenzer, Gerd, 2008. "Why Heuristics Work", Perspectives on Psychological Science, 3: 20-29.

Goda, Gopi Shah, Matthew R. Levy, Colleen Flaherty Manchester, Aaron Sojourner and Joshua Tasoff, 2019. "Who is a Passive Saver Under Opt-in and Auto-Enrollment", Working Paper No. 26078, National Bureau of Economic Research.

Gorman, W.M., 1996. "Two-Stage Budgeting”, in W.M. Gorman, C. Blackorby and A.F. Shorrocks (eds), Separability and Aggregation: The Collected Works of W.M. Gorman, Volume I, New York: Oxford University Press.

Gottlieb, Daniel and Olivia S. Mitchell, 2019. "Narrow Framing and Long-term Care Insurance", Journal of Risk and Insurance, 1-33.

Hare, Todd, Colin Camerer and Antonio Rangel, 2009. "Self-Control in DecisionMaking Involves Modulation of the vmPFC Valuation System", Science, 324(5927): 646-8.

Huffman, David, Raimond Maurer and Olivia S. Mitchell, 2017. "Time Discounting and Economic Decision-making in the Older Population", The Journal of the Economics of Ageing, https://doi.org/10.1016/j.jeoa.2017.05.001. 
Kahneman, Daniel, 2011. Thinking, Fast and Slow, New York: Farrar, Straus, and Giroux.

Karlan, Dean and Jonathan Zinman, 2012. "Borrow Less Tomorrow: Behavioral Approaches to Debt Reduction", Working Paper Financial Security Project at Boston College.

Kornelis, Chris, 2019. "The Biggest Ways People Waste Money", The Wall Street Journal, 14 June.

Liao, Chi, 2019a. "ADHD and Financial Distress", Review of Finance, forthcoming.

Liao, Chi, 2019b. "Supplemental notes to "ADHD and Financial Distress". Available at https://papers.ssrn.com/sol3/papers.cfm?abstract_id=3642852.

Lusardi, Annamaria, 2011. "Americans' Financial Capability", Report prepared for the Financial Crisis Inquiry Commission. Working paper, NBER. Available at https://www.nber.org/papers/w17103.

Lusardi, Annamaria and Olivia S. Mitchell, 2007. "Baby Boomer Retirement Security: The Roles of Planning, Financial Literacy, and Housing Wealth", Journal of Monetary Economics, 54: 205-24.

Lusardi, Annamaria and Olivia S. Mitchell, 2014. "The Economic Importance of Financial Literacy: Theory and Evidence", Journal of Economic Literature, 52(1): 5-44.

Lusardi, Annamaria, Pierre-Carl Michaud and Olivia S. Mitchell, 2017. "Optimal Financial Knowledge and Wealth Inequality", Journal of Political Economy, 125(2): 431-77.

Mandell, Lewis, 2008. "Financial Education in High School", in Annamaria Lusardi (ed.), Overcoming the Saving Slump: How to Increase the Effectiveness of Financial Education and Saving Programs, Chicago, IL: University of Chicago Press, pp. 257-79.

Martin, John and Arthur Keown, 2017. "A Tutorial on the Economics of Payday Lending: Loan Sharking or Risky Lending", available at https://papers.ssrn. $\mathrm{com} / \mathrm{sol} 3 /$ papers.cfm?abstractlid=2946399.

Melzer, Brian T., 2011. "The Real Costs of Credit Access: Evidence from the Payday Lending Market”, The Quarterly Journal of Economics, 126(1): 517-55.

Morgan, Donald P. and Michael Strain, 2008. "Payday Holiday: How Households Fare After Payday Credit Bans", Federal Reserve Bank of New York Staff Report No. 309.

Morse, Adair. 2011. "Payday Lenders: Heroes or Villains?", Journal of Financial Economics, 102(1): 28-44.

Norman, A., K. Brehm, M. Drake, A. Dyer, J. Frisby, C. Govil, C. Hinchey et al., 2008. "Decision Heuristics and Price Search", Working Paper, University of Texas, Austin, TX.

PACFL, 2008. "2008 Annual Report to the President of the President's Advisory Council on Financial Literacy", Washington, DC.

Ratcliffe, J., 1998. "Patients' Preferences Regarding the Process and Outcomes of High Technology Medicine: An Application of Conjoint Analysis to Liver Transplantation", Paper presented at the Health Economists' Study Group, University of Sheffield, January.

Reynolds, Cecil R. and Randy W. Kamphaus, 2013. "Attention-Deficit/Hyperactivity Disorder (ADHD)", in Diagnostic and Statistical Manual of Mental Disorders, 5th edn, American Psychiatric Association.

Ryan, M. and J. Hughes, 1997. "Using Conjoint Analysis to Value Surgical Versus Medical Management of Miscarriage", Health Economics, 6: 261-73. 
Semczuk, Nina, 2017. "Should You Open a Christmas Club Account?", 30 October, available at https://smartasset.com/checking-account/christmas-club-accounts.

Shefrin, Hersh, 2013a. "Tips for Reducing Stress as We Enter the Holiday Shopping Season", Huffington Post, 20 November.

Shefrin, Hersh, 2013b. "Spending and Borrowing on Black Friday and Cyber Monday", Huffington Post, 27 November.

Shefrin, Hersh, 2013c. "Who Will Overspend This Holiday Season?", Huffington Post, 17 December.

Shefrin, Hersh, 2013d. "Born to Spend? How Nature and Nurture Impact Spending and Borrowing Habits", Chase Bank White Paper.

Shefrin, Hersh, 2020. "Unfinished Business: A Multicommodity Intertemporal Planner-Doer Framework", Review of Behavioral Finance, 12(1): 35-68.

Shefrin, Hersh and Christina Nicols, 2014. "Credit Card Behavior, Financial Styles, and Heuristics", Journal of Business Research, 67: 1679-87.

Shefrin, Hersh and Richard Thaler, 1980. "A Multicommodity Intertemporal Planner-Doer Framework", Working Paper, Santa Clara University.

Shefrin, Hersh and Richard Thaler, 1988. "The Behavioral Life Cycle Hypothesis", textit Economic Inquiry, XXIV: 609-43.

Skiba, Paige Marta and Jeremy Tobacman, 2011. "Do Payday Loans Cause Bankruptcy?", Working Paper, Vanderbilt Law and Economics Research Paper No. 11-13.

Sullivan, Paul, 2019. “'Deciding How to Decide': Even the Rich Need Advice on Budgeting”, New York Times, 11 January.

Thaler, Richard, 1985. "Mental Accounting and Consumer Choice", Marketing Science, 27(1): 15-25.

Thaler, Richard and Shlomo Benartzi, 2004. "Save More Tomorrow: Using Behavioral Economics to Increase Employee Saving", Journal of Political Economy, 112(1), pt. 2: S164-87.

Thaler, Richard and Hersh Shefrin, 1981. "An Economic Theory of Self Control", Journal of Political Economy, 89(2): 392-406.

Thaler, Richard and Cass Sunstein, 2008. Nudge: Improving Decisions About Health, Wealth, and Happiness, New Haven, CT: Yale University Press.

Wong, Kristin, 2018. "What I Learned From Tracking My Spending for a Month", New York Times, 28 November. 